\title{
Prevalence and Pattern of Road Traffic Accident and Injuries among Commercial Motorcyclists in Sokoto Metropolis, Sokoto, North-Western Nigeria
}

\author{
Lawal N1, Oche $\mathrm{MO}^{2}$, Isah BA², Yakubu $\mathrm{A}^{3}$ and Danmadami AM² \\ ${ }^{1}$ Katsina State Health Service Management Board, Katsina, Nigeria \\ ${ }^{2}$ Department of Community Health, Usmanu Danfodiyo University Teaching Hospital, \\ Sokoto, Nigeriawin \\ ${ }^{3}$ Department of Medicine, Usmanu Danfodiyo University Sokoto
}

Research Article

Volume 2 Issue 2

Received Date: March 04, 2019

Published Date: March 08, 2019

DOI: $10.23880 /$ jqhe- 16000113

*Corresponding author: Nasiru Lawal, Katsina State Health Service Management Board, Nigeria, Tel: 08069756875; Email: formular32@yahoo.co.uk

\section{Abstract}

Motorcycle accidents contribute significantly to the number of road traffic accidents (RTAs) in many cities in Northern Western Nigeria. This study was carried out to determine the prevalence and pattern of RTAs among commercial motorcyclists in Sokoto metropolis Nigeria. A descriptive, cross sectional study was carried out among commercial motorcyclist's riders in 2014 in Sokoto metropolis Nigeria. The instrument of data collection was a semi-structured interviewer administered questionnaire. Data was analysed using SPSS version 20.0. A total of 307 male commercial motorcyclists participated in the study, out of which 194 (63.2\%) had been involved in RTAs since they started riding. Seventy two percent (72\%) attributed the last accident to Motor vehicle hit/Obstruction, Almost all were not wearing helmets when the accident occurred and sustained different form of injuries during the accident, out of which majority (37\%) had Motorcycle - Motorcycle collision, lower limb was the part mostly affected $33.5 \%$ and bruises were the commonest injuries sustained.

Keywords: Commercial Motorcyclist; Road Traffic Accident; Injuries

\section{Introduction}

Road traffic accidents occur when a vehicle collides with another vehicle, pedestrian, animal, road debris, or other stationary obstruction, such as a tree or utility pole, it is an accident which takes place on the road between two or more object, one of which must be any kind of moving vehicle [1]. Approximately 1.35 million people die each year as a result of road traffic crashes. The 2030 Agenda for sustainable development has set an ambitious target of halving the global number of deaths and injuries from road traffic crashes by 2020. Road traffic crashes cost most countries $3 \%$ of their gross domestic product. More than half of all road traffic deaths are among vulnerable road users: pedestrians, cyclists, and motorcyclists. Road traffic injuries are the leading cause 


\section{Journal of Quality in Health Care \& Economics}

of death for children and young adults aged 5-29 years [2]. The National Bureau of Statistics in Nigeria shows 11,363 road accidents were recorded in 2016. The report said speed violation was reported as the major cause of the accidents in 2016, which accounted for 33.86 per cent of the total road accidents reported $[3,4]$.

In Sokoto state about 1,468 cases of road traffic accidents were registered by FRSC Sokoto command between 2011- 2013 with 95 cases of fatality at the accident spot [5]. An okada (also: Kabu kabu, Achaba, Going, Inaga) is a commercial motorcycle used as a vehicle for hire in Nigeria, it constituted a significant proportion of modal choice of commuters in many cities since the late 80 's [6]. It was reported that in 1995, an estimated 45,000 motorcycles were in use for public transportation in Lagos metropolis alone [6]. In 2004 and $2005,52 \%$ of all motor vehicle license plates were for motorcycles, and about 2\% of the 2004 motorcycle license plates were produced for commercial purposes [7]. In Sokoto metropolis, motorcycle accidents constituted $40 \%$ of road traffic accidents in 2009 [8].

Road traffic death and injuries can be prevented [4]. The key to successful prevention lies in the commitment of all relevant sectors, public and private-health, transport, education, finance, police, legislator, manufacturers, foundation and the media. This study is done aim to determine Prevalence and Pattern of Road Traffic Accident and injuries among commercial motorcyclists in Sokoto metropolis, Sokoto, North-Western Nigeria. Motorcycle injuries have not received the attention they deserve partly because of lack of local data, and the public policy responses to this epidemic have been muted at regional and national level.

\section{Material and Methods}

Sokoto is situated in the North- Western part of Nigeria. The State was created from Old North- western in 1976, it assumed its present form after the creation of Kebbi State (in 1991) and Zamfara State (in 1996) It is bounded by Zamfara State to the South, Kebbi state to the west, Katsina State to the east and Niger Republic to the North. The State has 23 Local Government with Sokoto Metropolis being the capital, and it comprises the Sokoto North, Sokoto South and some part of Dange shuni, kware and Wamako Local Government Area. The metropolis is the seat of Government and popularly Called the seat of caliphate, and it's the capital of Sokoto state, it lies between longitudes 0511 to 1303 east, Latitude 1300 North and covers area of 60,33 square $\mathrm{km}$. The average projected population of the state for 2015 is $4,886.888$ (UNFPA, 2015) with the metropolitan having $(2,425,969)$ Sokoto covers a total Land area of $26,595,000 \mathrm{~m} 2$ thus constituting about $59 \%$ of the country total land mass. The people are mainly Hausa/Fulani; others are Zabarmawa, and other various tribes from different part of the country. Islam is the predominant religion. The people are mainly farmers. However some engage in art work like shoe making, tanning, Black- Smiting and other various kind of trading. There are four Motor Parks within Sokoto metropolis with Central motor Park being the largest others are Kara Motor park, Illela garage Motor park and Kalambaina Motor Park, Kwannawa, Round mai ruwa, Hubbare and Dandima garage. The commonest mode of transportation in Sokoto metropolis was commercial motorcycle they have Association called (ACOMORAN) that is" Amalgamated Commercial Motorcycle Riders Association of Nigeria" which is headed by a Chairman and the secretary, with different units headed by the unit chairman, they have a total numbers of about 60,000commercial motorcycle riders in the state Acomoran, et al. And those in the metropolis constitute about 40,000 and about 15,000 are registered with the association and operate daily register in their unit in order to carry out their services, the units are categories below.

For Sokoto North there are 12 units and had 2556 registered riders as the time of this study.

For Sokoto south there are 24 units these constitutes about 8000 riders but only about 3048 had registered with the association as the time of this study.

For Dange Shuni there are 18 units with 2,548 Riders registered with the association as the time of this study.

For Wamako LGA there are the following 36 units these constitute about 6000 Riders with about 4,233 registered one, and kware has about 1200 registered members as the time of this study.

A cross sectional descriptive study design was employed to determine the knowledge, attitude and compliance with road safety measures among commercial motorcyclists. The study population consisted of registered commercial motorcyclists that operate mainly in metropolis and have spent at least 6 months in commercial motorcycling business. All persons that have not met these criteria were excluded from participating in the study. 
A multistage sampling technique was adopted for the study.

Stage I: This involved the selection of units by simple random technique using the balloting method to select $25 \%$ of the units in each of the metropolitan local government areas. (Sokoto North 12, Sokoto South 24, Wamako 36, Dange Shuni 18, and Kware 4) that is Three, Six, Nine, Five, and one units respectively, were enrolled into the study (sample frame).

Stage II: Therefore proportional allocation was used to select the study respondents (sample unit) from the sample frame. There after Systematic sampling was used to select the study subject.

A pre-tested structured interviewer administered questionnaire was used to collect the data from 307 commercial motorcyclists who consented; the questionnaire was pretested in a different commercial motorcycle station located in another Local Government Area away from that of the study after translation and back translation to ensure standardization. The data collection took place from the 30th November to 30th of December 2014 and was carried out by the six trained research assistants. Data collected was entered, validated, and analyzed using SPSS software version 20.0.

\section{Ethical Consideration}

Before embarking on the study permission was sought from the Sokoto state ministry of health ethical review committee. Permission was also obtained from the chairman of amalgamated commercial motorcycle riders association of Nigeria (ACOMARAN) equally; each respondent was briefed and adequately informed on the purpose of the study, after which their consent was sought. The respondents were all assured of their privacy and confidentiality on whatever information they would give.

\section{Limitation of the Study}

None response and excessive demand of incentives made some targeted riders non accessible for the study.

\section{Results}

\section{Socio-Demographic Characteristics}

A total of 307 respondents were studied and majority of them (72.4\%) were within the age range of 20-29 years. All the respondents interviewed were males with $77.2 \%$ of them reported Hausa as their ethnic group and $93.0 \%$ of them indicated Islam as their religion. In terms of educational background, $41.0 \%$ of the respondents attended secondary school while $24.1 \%$ and $18.6 \%$ attended Quranic and primary schools. Over half (54.1\%) of the respondents are married. Majority (79.8\%) of the respondents did not receive any form of formal training before commencement of their business. Detail of the socio-demographic characteristics of the respondents is summarized in Table 1-3.

\begin{tabular}{|c|c|}
\hline Variables & n (\%) \\
\hline \multicolumn{2}{|c|}{ Age (Years) } \\
\hline $19-0 \mathrm{ct}$ & $22(7.1)$ \\
\hline $20-29$ & $153(49.0)$ \\
\hline $30-39$ & $102(32.7)$ \\
\hline $40-49$ & $27(8.7)$ \\
\hline$\geq 50$ & $3(1.0)$ \\
\hline Mean Age $=28.6, \pm$ & \\
\hline \multicolumn{2}{|c|}{ Sex } \\
\hline Male & $307(100)$ \\
\hline Female & $0(0)$ \\
\hline \multicolumn{2}{|c|}{ Marital status } \\
\hline Single & $118(38.4)$ \\
\hline Married & $166(54.1)$ \\
\hline Separated & $13(4.2)$ \\
\hline Divorced & $10(3.3)$ \\
\hline \multicolumn{2}{|c|}{ Religion } \\
\hline Islam & $293(95.4)$ \\
\hline Christianity & $14(4.6)$ \\
\hline \multicolumn{2}{|l|}{ Ethnicity } \\
\hline Hausa & $237(77.2)$ \\
\hline Fulani & $46(15)$ \\
\hline Yoruba & $9(2.9)$ \\
\hline Igbo & $6(2.0)$ \\
\hline Others & $9(2.9)$ \\
\hline \multicolumn{2}{|c|}{ Education } \\
\hline Primary & $57(18.6)$ \\
\hline Secondary & $126(41.0)$ \\
\hline Tertiary & $47(15.3)$ \\
\hline Qur'an & $74(24.1)$ \\
\hline Others & $3(0.9$ \\
\hline \multicolumn{2}{|c|}{ Motorcycle Riding Training School attendance } \\
\hline Yes & $62(20.2)$ \\
\hline No & $245(79.8)$ \\
\hline
\end{tabular}

Table 1: Socio-demographic profile of respondents.

A total of 194 (63.2) had been involved in road traffic accidents since they started riding motorcycles. Among those who were ever involved in accidents, 139 (71.6\%) 
attributed the last accident to Motor vehicle hit/obstruction and 72(37.1\%) of them reported colliding with another motorcycle during the most recent accident. The parts of the body mostly affected was lower limb 65 (33.5\%) followed closely by upper limb 56 (28.9\%), bruise 127 (65.5\%) was the commonest injury sustained

\begin{tabular}{|c|c|}
\hline \multicolumn{1}{|c|}{ Variable } & n (\%) \\
\hline Accident Involvement \\
\hline Yes & $194(63.2)$ \\
\hline No & $113(36.8)$ \\
\hline Causes & $139(71.6)$ \\
\hline Motor vehicle hit/Obstruction & $24(12.4)$ \\
\hline Over speeding & $15(7.7)$ \\
\hline Dangerous driving & $6(3.1)$ \\
\hline Bad roads & $5(2.6)$ \\
\hline Tyre burst & $2(1.0)$ \\
\hline Route violation & $2(1.0)$ \\
\hline Use of GSM phone while driving & $1(0.5)$ \\
\hline Dangerous overtaking & $\mathbf{1 9 4}$ \\
\hline Total &
\end{tabular}

Table 2: Cause of RTA among those involved in Accident.

\begin{tabular}{|c|c|}
\hline Pattern & n (\%) \\
\hline \multicolumn{2}{|l|}{ Collision } \\
\hline Motorcycle-Motorcycle & $72(37.1)$ \\
\hline Motorcycle-Vehicle car & $67(34.5)$ \\
\hline Motorcycle-Stationary object & $36(18.6)$ \\
\hline Motorcycle-pedestrian & $15(7.7)$ \\
\hline Others & $4(2.1)$ \\
\hline \multicolumn{2}{|l|}{ Body affected } \\
\hline Lower limb & $65(33.5)$ \\
\hline Upper limb & $56(28.9)$ \\
\hline Head and Face & $52(26.8)$ \\
\hline Trunk & $14(7.2)$ \\
\hline Others & $7(3.6)$ \\
\hline \multicolumn{2}{|l|}{ Injury sustained } \\
\hline Bruise & $127(65.5)$ \\
\hline Laceration & $48(24.7)$ \\
\hline Fracture & $9(4.6)$ \\
\hline Burns & $8(4.1)$ \\
\hline Others & $2(1.0)$ \\
\hline
\end{tabular}

Table 3: Pattern of RTA and Type of injuries among riders with history of previous RTA.

\section{Discussion}

This study showed that nearly half $(49.0 \%)$ of the respondents were within the age range of 20-29 years, and a mean age of 28.6 years this is in consonance with findings obtained by Oboirien MO, et al. and Sufiyan MB, et al. $[9,10]$ in Ibadan, who found the Age range of their respondents to be 20-29years, the Similarity in the age range for the respondents in the two centers (Zaria and Ibadan) may not be unrelated to the high level of unemployment among the youths in the country which has forced the youths to take to motorcycles riding as business to earn a living. Majority (74.9\%) of the commercial motorcyclist had formal education which is similar to the findings of Oboirien MO, et al. [9] conducted in Zaria where $(70 \%)$ of their subjects had formal education, however the figure obtained from this study is lower than the one obtained by Sufiyan MB, et al. and Owoaje ET, et al. [10,11] where $(91.6 \%)$, and $(94.2 \%)$ had formal education respectively, this differences may be due to higher number of unemployed graduate in the south west region more than north west region of Nigeria.

This study revealed about 194 (63.2\%) of the respondents were involved in the road traffic accident, this is higher than the findings obtained by Sufiyan MB, et al. and Oginni FO, et al. [10,12] who found the respondents involves in accident to be $(55.6 \%)$ and $(45.3 \%)$ respectively, however the figure obtained from this study is lower than that of who found the respondents involved in accident to be $(76.4 \%)$, (74.8\%) and $(68 \%)$ respectively $[10,13,14]$.

The major cause of road traffic accident in the study area was motor vehicle hit/obstruction $(71.6 \%)$, this is similar to the finding obtained by Ofonime E [15], who found motor vehicle hit (57\%) the commonest cause of road traffic accident among the commercial motorcyclist rider. This may not be unrelated to the fact that the easiest way to commute is by the aid of a motorcycle as is the case in most Nigerian cities where patronage of commercial motorcyclist cuts across socio- economic status as some do use them to navigate the poor road network and sometimes to beat traffic. This makes the rider to stay at inappropriate positions between motor vehicles and as a result of this they may be hit by motor vehicle. This is explained by 'Looked but failed to see' theory where they looked but failed to see error according to Dongo AE, et al. [16]. This refers to a set of circumstances where a driver accounts for an accident in terms of failing to detect another road user in time to avoid a collision. It was noted that the size of motorcyclists render them more likely to be obscured by other vehicles also revealed that statistically, motorcyclists appear to be involved in more accidents where the driver failed to detect them in time $[15,17]$. 


\section{Journal of Quality in Health Care \& Economics}

However, the findings obtained from this study differed from the one obtained by who found over speeding (31.5\%, 26.5\% and $25 \%$ respectively) to be the major cause of road traffic accident $[12,14,18]$. Findings from this study showed that over speeding was the second major cause of accident. In the USA, records from the department of transport's national highway safety administration (NHTSA) (2005) showed that there were 4,553 deaths from motorcycle accidents with $48 \%$ of these deaths resulting from over speeding. This study revealed the commonest pattern of road traffic accidents among those involved in the accident was motorcyclemotorcycle collision (37.1\%), this finding is in consonance with one obtained by NHTSA [8] who observed the pattern of road traffic accident among the respondents to be motorcycle-motorcycle collision (43.6\%). However the findings obtained from this study were different from the one obtained by Sufiyan MB, et al. [10], who found that motorcycles involved in collision with a car $(28 \%)$ to be the commonest pattern. The reason for this may be attributed to the fact that there are more motor vehicles than motorcycles in the south where taxi business is more lucrative than "okada" unlike Sokoto where the major means of commercial transportation is kabu-kabu.

The part of body mostly affected with injury among the respondents involved in the road traffic accident in this study was lower limb (33.5\%), followed by upper limb $(28.9 \%)$ this is similar to the finding obtained by who found the lower limb followed by upper limb as part of the body commonly affected $[9,14,15]$. This is in contrast to the findings obtained from findings of Sufiyan MB, et al. [10] in Ibadan where the upper limbs were the mostly affected part $(12.5 \%)$ followed by lower limbs (3.7\%). However from Naddumba EK [19], found that head injury was the most frequently occurring injury followed closely by injuries of the extremities. The reason why the lower limb was the more affected part in the injury was due to the fact that it's the most exposed area to hit by car and other motorcycles in terms of collision. Types of injury sustained by the riders that are involved in the RTA in this study showed that Bruises were the commonest $(65.5 \%)$ injury sustained followed by laceration $(24.7 \%)$, this is similar to the findings of Yunusa (2014) in same zone were $66.7 \%$ of those that were involved in accidents sustained bruises, and lacerations. In other studies Ogunmodede TA, et al. [14] observed bruises/abrasion as the commonest injury sustained by their respondents. This may be due to inappropriate practice where motorcyclists do not wear appropriate protective devices always during the business. These findings contradict those of where they observed fracture of the limb to be the commonest injury followed by head injury [20-22].

In conclusion, motorcycle injuries constitute a major but neglected emerging public health problem. The findings in this study shown non compliances use of protective equipment by commercial motorcyclists which has expose both the riders and passenger to sustain different kind of injuries, there is needs to enforce laws that will ensure use of protective equipment by motorcycles' and passengers. There should be implementation and enforcement of laws that will safeguard speed limits among commercial motorcyclists. Stakeholders in the road construction industry should be brought on board to ensure future road construction and renovations have reservation for motorcyclists.

\section{References}

1. Asogwa (1999) Road Traffic Accidents in Nigeria: a hand book for all road users. $2^{\text {nd }}(E d n$.$) , SNAAP Press$ Ltd, Enugu.

2. WHO (2018) Road traffic injuries.

3. Adebowal S (2017) NBS releases statistics on road accidents in Nigeria.

4. Olagunju K (2010) Fleet management strategies, Nigeia. $1^{\text {st }}$ (Edn.), FRSC, pp: 1-145.

5. WHO (2004) Developing an effective and appropriate helmet for the protecting the vulnerable road user.

6. WHO (2014) Road Safety Annual Report.

7. Gbadamosi (2004) Spatial Analysis of road Traffic Accidents in Nigeria Olabisi Onabanjo University. Journal of Environmental Management and Safety 2(1).

8. NHTSA (2007) Motorcycle Traffic Safety Fact sheet.

9. Oboirien MO, Adegbala MO, Agbo PS, Adedeji BK (2013) Determining injury severity amongst victims of motorcycle accidents in Sokoto, north west Nigeria. Global Journal of Medical Research 13(7).

10. Sufiyan MB, Ahmad SM (2013) Knowledge, attitude and compliance with safety protective devices among commercial motorcyclists in Tudun-Wada Zaria, North-Western Nigeria. Ann Nigerian Medicine 6(2): 80-86. 


\section{Journal of Quality in Health Care \& Economics}

11. Owoaje ET, Amoran OE, Osemeikhain, Ohnoferi OE (2005) Incidence of road traffic accidents and pattern of injury among commercial motorcyclists in a rural community in south western Nigeria. Journal of Community Medicine and Primary Health Care 17(1): 7-12.

12. Oginni FO, Ugboko VI, Adewole RA (2007) Knowledge, attitude, and practice of Nigerian commercial motorcyclists in the use of crash helmet and other safety measures. Traffic Inj Prev 8(2):137141.

13. Yunusa U, Lawal UB, Idris A, Garba SN (2014) Occupational Health hazards among commercial motorcyclist in Ahmadu Bello University Zaria. Journal of Nursing and Health Science 3(1): 46-52.

14. Ogunmodede TA, Akangbe CA (2013) Effect of road safety information availability and utilization on commercial motorcycle accident in Oyo Nigeria. International Journal of Library and Information Science 5(3): 68-76.

15. Ofonime E (2012) Prevalence and pattern of road traffic accident among commercial motorcycle in a city in southern Nigeria. Education Research 3(6): 537-542.
16. Dongo AE, Kesieme EB, Eighemherio A, Nwokike O, Esezobor E, et al. (2013) Motorcycle Related Injuries among Rural Dwellers in Irrua, Nigeria: characteristics and correlates. Emergency Medicine International, pp: 4.

17. Sabey B, Staughton GC (1975) Interacting Roles of Road Environment, Vehicle and Road User, in Accidents. 5th International Conference of the International Association for Accident Traffic Medicine. London.

18. Williams MJ, Hoffmann ER (1999) Alcohol use and motorcycle accidents. Accident Analysis and Prevention 11(3): 199-207.

19. Naddumba EK (2004) A cross sectional retrospective study of boda injuries at Mulago Hospital in KampalaUganda. East and Central Africa Journal of Surgery 4(6): 44-47.

20. Nwadiaro HC, Ekwej KK, Akpayak IC, Shitta H (2011) Motorcycle injuries in north-central Nigeria. Niger J Clin Pract 14(2): 186-189.

21. Bamidele JO, Adebimpe WO, Adeoye OA (2012) Morbidity and Mortality Pattern among Commercial Motorcyclists in Osogbo Metropolis in South Western Nigeria. Journal of Contemporary Medicine 2(1): 1316. 